\title{
Towards Culture 3.0 - Performative space in the public library
}

Jochumsen, Henrik; Skot-Hansen, Dorte; Rasmussen, Casper Hvenegaard

Published in:

International Journal of Cultural Policy

DOI:

$10.1080 / 10286632.2015 .1043291$

Publication date:

2015

Citation for published version (APA):

Jochumsen, H., Skot-Hansen, D., \& Rasmussen, C. H. (2015). Towards Culture 3.0 - Performative space in the public library. International Journal of Cultural Policy, 1-13. https://doi.org/10.1080/10286632.2015.1043291 


\section{Towards Culture 3.0 - performative space in the public library}

\section{Henrik Jochumsen, Dorte Skot-Hansen \& Casper Hvenegaard Rasmussen}

To cite this article: Henrik Jochumsen, Dorte Skot-Hansen \& Casper Hvenegaard Rasmussen (2015): Towards Culture 3.0 - performative space in the public library, International Journal of Cultural Policy, DOI: 10.1080/10286632.2015.1043291

To link to this article: http://dx.doi.org/10.1080/10286632.2015.1043291

Published online: 24 Jun 2015.

Submit your article to this journal $₫$

Џلll Article views: 160

Q View related articles $\sqsubset$

View Crossmark data ¿

Citing articles: 1 View citing articles 5 


\title{
Towards Culture 3.0 - performative space in the public library
}

\author{
Henrik Jochumsen*, Dorte Skot-Hansen and Casper Hvenegaard Rasmussen \\ Centre for Cultural Policy Studies, Royal School of Library and Information Science, \\ University of Copenhagen, Birketinget 6, 2300 Copenhagen S, Denmark
}

(Received 25 November 2014; accepted 15 April 2015)

\begin{abstract}
The aim of this article is to analyse and discuss the development of performative spaces in public libraries from a cultural policy perspective. First, a framework of three concepts of culture, 1.0-3.0, is used as a tool to analyse the overall development of public libraries. Against this background, we introduce the notion of performative spaces in public libraries by highlighting Nordic examples. The tendency can also be seen on a broader level in European and North American libraries, where a 'performative turn' can be seen as the relationship between the library and its users, especially the younger 'digital natives'. The rationales behind the emergence of performative spaces in public libraries are analysed and discussed: democratisation, empowerment and economic impact. This article concludes that the performative spaces are legitimized by multiple rationales in the same way as cultural policies and cultural institutions are legitimised today.
\end{abstract}

Keywords: cultural policy; public libraries; performative space; economic impact; democratization; empowerment

\section{Introduction}

In recent years we have witnessed a 'performative turn' (Fischer-Lichte 2008) in which cultural institutions such as theatres, museums and public libraries have increasingly embraced concepts such as user-participation, user-involvement, userdriven innovation and co-creation. This tendency can be seen in close connection with technological developments in general, and particularly the rise of the socalled 'digital native' generations, born from the late 1990s after the introduction of digital technology. In the case of public libraries, performative spaces, where users are given the potential to be creative and innovative, are now being established in both a European and a North American context. Many public libraries today thus provide artistic tools for their users as well as supporting the dissemination of the user's own artistic, musical or literary products. Others offer various types of 'makerspaces' or 'hackerspaces' where users can innovate through co-creating. In the first century of this decade 'from collection to connection' was a popular catchphrase for public libraries, now however the idea of 'from collection to creation' plays a key role in the current library discourse, as reflected in the quotation below:

*Corresponding author. Email: jrd560@iva.ku.dk 
The creation library is a library which has extended its role and become a place where media conveying information, knowledge, art and entertainment are created. It is a library that houses a range of equipment and facilities to help, authors, editors, performers and other creators to prepare new work, alone or in groups, in new or old media, for personal use or widespread distribution. (American Library Association 2011, p. 5)

The aim of this article is to analyse and discuss the cultural modes and rationales of the cultural policy that lies behind the development from collection to creation and how it has resulted in the establishment of a new participatory space in the public library. The framework used to describe this development is inspired by three concepts of culture, from 1.0 to 3.0 , developed by the cultural economist Sacco (2011). This article builds on Sacco's definitions of Culture 1.0-3.0 as inspiration and a point of departure. The aim of the article is not to analyse or discuss Sacco's use of these concepts in the context of the EU structural funds programming. Against this background, we introduce the notion of performative spaces in public libraries by highlighting Nordic examples. The tendency can also be seen on a broader level in European and North American libraries, where a 'performative turn' can be seen as the relationship between the library and its users, especially the younger 'digital natives'. Here we differentiate between 'the creative space', where libraries support the creativity of citizens and especially young people, and 'the innovation space', which addresses the 'maker-culture' through so-called 'makerspaces' and 'hackerspaces'. The descriptions of these examples are based on our own observations, interviews and/or documents obtained over the last five years. Finally we will discuss the rationales behind the emergence and rapid spread of performative spaces in public libraries as we perceive them: democratisation, economic impact and empowerment. Accordingly we ask whether the orientation of public libraries towards a more participatory approach should be seen as a revival/ rethinking of the strategy of 'cultural democracy' seen in the 1970s, aimed at strengthening individual and group identity and empowerment or rather as part of a new, more subtle rationale of economic impact. Or should it simply be seen as an attempt to legitimize the public library by making it more visible in a time characterised by a declining number of users, decreasing political interest and financial cuts?

\section{Towards Culture 3.0}

In connection with the EU 2014-2020 structural funds programming Sacco has developed three concepts of culture: 1.0, 2.0 and 3.0. While Culture 1.0 basically revolves around the concept of patronage - either private or public - Culture 2.0 can be seen as a new relationship between cultural production and the generation of economic value, dominated by the expansion of the cultural and creative industries. This phase has been characterised by the explosion in the size of the cultural markets. On the other hand, Culture 3.0 revolution is characterised by an explosion in the number of producers, making it difficult to distinguish between cultural producers and users (Sacco 2011). We will first briefly introduce Culture 1.0 and 2.0 and the way that they are reflected in the public library as a background for discussing the emergence of 3.0 and its impact on the public library. 


\section{Culture 1.0 - patron state/artist}

Culture 1.0 revolves around the concept of patronage, which is typical of pre-industrial economy. The provision of culture is secured by the individual initiative of patrons such as the Hapsburgs and the Bourbons, who employed artists to decorate their palaces and to perform for their pleasure (Hillman-Cummings and Katz 1987). This model can, according to Sacco, only support a very limited number of cultural producers and very limited audiences. With the industrial economic revolution and the following political revolutions leading to the modern nation states, culture was seen as a universal right and different forms of 'public patronage' emerged (Sacco 2011 , p. 2). This tendency is reflected in the patron model where the state funds the fine arts through arms-length councils (Hillman-Chartrand and McCaughey 1989). The English cultural sociologist Raymond Williams describes this ideal role of the state as a gerent for producing and distributing culture as cultural policy 'proper', as compared to cultural policy as 'display', making a sharp distinction between the rationale of enlightenment on one side and the rationale of national aggrandizement and economic reductionism on the other side (Williams 1984, cited in McGuigan 2004).

Public libraries can clearly be related to Sacco's concept of Culture 1.0. The most prominent example of the private patronage of libraries with free public access is the Scottish-American businessman and philanthropist Andrew Carnegie. Carnegie financed 1679 library buildings in America between 1886 and 1919 (Mickelson 1975, p. 132) and had several motives for his generous donations to libraries, which did not differ significantly from public engagement in libraries today. For Carnegie the libraries were a cradle of democracy, a breeding ground for self-made men, a centre for self-improvement and entertainment for the workers. In an American context, private patronage, such as the Bill and Melinda Gates Foundation, still plays an important role in the development of libraries (Stevenson 2010), but public patronage is today without doubt the main source of funding for libraries. If we look at the Nordic countries, public patronage is almost the only source of public library funding, and libraries are seen as a cornerstone in the strategy of democratisation of culture.

\section{Culture 2.0 - state/market}

According to Sacco, we entered the Culture 2.0 phase at the turn of the twentieth century, where the technological possibility of cultural mass markets became a reality. In this advanced phase, public policies were

increasingly addressing not only the issues of enhancing access of audience to cultural products and experiences, but also of enhancing productive and entrepreneurial capacities in these sectors in the light of their increasingly relevant contribution to the macroeconomic level of activity. (Sacco 2011, p. 3)

This instrumental tendency is not only seen in connection with the cultural and creative industries, but also in connection with the extensive use of art and culture in urban regeneration, city-branding through iconic cultural institutions, and the use of events as 'inauthentic, instrumental spectacles to the benefit of hit-and-run tourism' (Sacco 2011, p. 9). 
In Culture 2.0 the value of cultural and artistic resources in society is perceived as economic impact. This discourse can be seen in cultural policy as a consequence of the economic downturn beginning in the 1980s (Vestheim 1994). It can be debated whether this instrumentalization of cultural policy is something new or if the Enlightenment rationale can also be seen as instrumental, with its emphasis on cultural education as a means towards enlightened democracy (Skot-Hansen 2002). But there is no doubt that the ideological discourse of 'marketization' and 'managerialization' has invaded the public sector in cultural policy. As the cultural analyst Jim McGuigan states: 'Market reasoning and public-sector marketing represent a pervasive neoliberal ideology that frames the policies of social-democratic governments just as much as - and sometimes more than - conservative administrations' (McGuigan 2004, p. 47).

Even though public libraries are basically non-profit organisations, it is not difficult to document the logic marketing in library practice. Over the last twenty years library collections have become more and more demand-oriented and librarians increasingly refer to the users as 'customers' (Hvenegaard Rasmussen and Jochumsen 2007). This tendency is emphasised when libraries are designed as 'marketspaces' with focus on the customer as seen in the Idea Stores in London, which are flagship libraries branded as chain stores following the concept of Starbucks. Another example is the Experience Library in Cerritos, LA, which is built following the concept of J. Pine and J.H. Gilmore's The Experience Economy (1999).

Libraries have also become an integrated part of urban development. Cultural institutions such as opera houses, concert halls and especially art museums have been part of an economic strategy based on city-branding and image since the 1980s (Bianchini and Parkinson 1993). Public libraries have become a part of economic strategy based on city branding within the last decade (Skot-Hansen et al. 2013). Throughout North America there is a growing trend for cities to use public libraries as vehicles for economic development, where new main libraries are built to stimulate inner-city revitalisation, and branches are integral catalysts in neighbourhood renewal programs (Kemp and Trotta 2008). The Seattle Public Library of 2004 is probably the best example of an iconic library building explicitly planned as an integrated part of urban branding. More recent examples in the Northern European countries are Amsterdam's hyped Openbare Bibliotheek and the imposing new Birmingham Library.

\section{Culture 3.0 - cultural producers/users}

Sacco characterises the Culture 3.0 revolution as 'the explosion of the pool of producers, so that it becomes increasingly difficult to distinguish between cultural producers and users. Simply, they become interchanging roles on the basis of non-market-mediated exchange' (Sacco 2011, p. 3). The characteristics of the 3.0 revolution are, on one side, the transformation of audience into practitioners within active, engaging reception patterns, and on the other side the pervasiveness of culture, which is no longer used as entertainment, but has become an essential ingredient of everyday life. Active cultural participation is defined as

a situation in which individuals do not limit themselves to absorb passively the cultural stimuli, but are motivated to put their skills at work: thus, not simply hearing music, but playing; not simply reading texts, but writing, and so on. (ibid., p. 5) 
According to Sacco, the strategic importance of active cultural participation include, among other things, innovations, new entrepreneurship models and soft power. In short, he argues that cultural participation may act as a driver of endogenous economic growth.

\section{The performative turn and the digital natives}

Focusing on cultural participation one can speak of a 'performative turn', that creates new relationships between art and audiences (Fischer-Lichte 2008). This is especially relevant when speaking about the new generations of 'digital natives', the generations born since the late 1990s after the general introduction of digital technology (Palfrey and Gasser 2008). As 'prosumers' these generations not only consume but also produce culture (Ritzer et al. 2012). Social media and interactive computer games are an integrated part of their everyday life and the potential to remix, download and share their own productions within music, text and pictures are numerous in a 'convergence culture' (Jenkins 2006). One result of this development is the spread of the so-called DIY (Do It Yourself) culture. The origin of DIY-culture is found in zines (non-commercial small-circulation publications), underground scenes, punk-ideology and an ideology of anti-consumerism, the new generations of digital natives and their predisposition for user involvement and cocreation have been a driving force behind the widespread nature of this culture (Spencer 2005). Today the concept of DIY does not necessarily contain any subcultural connotations and it is often used to describe almost anything 'made by yourself'.

If cultural institutions, traditionally characterised by order and one-way communication, are to be relevant for the digital natives, they must provide spaces that facilitates creation and co-creation. The American museologist Nina Simon discusses the challenges posed by active participation culture in her book The Participatory Museum (Simon 2010). Here she defines a participatory cultural institution as a place where visitors can create, share, and connect with each other around content:

Create means that visitors contribute their own ideas, objects, and creative expression to the institution and to each other. Share means that people discuss, take home, remix, and redistribute both what they see and what they make during their visit. Connect means that visitors socialize with other people - staff and visitors - who share their particular interests. Around content means that visitors' conversations and creations focus on the evidence, objects, and ideas most important to the institution in question. (Simon 2010, p. iii)

The public library is challenged by the emergence of Culture 3.0. The 'performative space' has been added to the more traditional spaces for inspiration, learning and meeting. In Denmark, the concept of performative space was first presented in a new library model developed on behalf of the Committee on Public Libraries in the Knowledge Society (Danish Agency for Library and Media 2010), and a detailed description can be found in the article 'The four spaces - A new model for the public library' (Jochumsen et al. 2012). The model has since been used as scaffolding in the 'Model Program for Public Libraries', an interactive site addressing architects and library designers (Danish Agency for Culture 2014). The idea of performative spaces has become widespread especially in the Nordic library 
world, where it has been incorporated both in overall strategies for library development and actual physical spaces. In the following we will present the background for the development of performative spaces, and discuss some examples in the Nordic public libraries.

\section{Performative spaces in the public library}

In a public library the concept 'performative space' is used to describe spaces in which the library's users are inspired to create new artistic expressions or are given the ability to design, create and produce various kinds of products or cultural artefacts in interaction with other users and professionals. In the performative space users have access to tools such as musical instruments, recording equipment, 3D scanners, laser cutters and printers and they can get advice and support in connection with their creative activities through workshops with professional artists, designers, multimedia developers etc. Finally, the performative space is a platform for mediation, supporting publishing and distribution of the users' products, and providing stages for their activities.

The Nordic public library has since the 1960s offered a limited performative space by providing stages for amateur performances or exhibition areas for local artists. There were even a few examples of video-workshops or writing-workshops in Danish libraries dating back to the 1970s. Noticeably the library has within the last ten years changed its identity where keywords such as doing, making, publishing, working, playing and experiencing have become central. Today, the creation of performative spaces is seen as an integrated part of new library buildings, in the reconceptualization of older libraries, and the notion plays a key role in current strategic visions and library policies.

In the following examples of performative spaces in public libraries we distinguish between creation space and innovation space. The creation space represents performative spaces in libraries where artistic tools, especially music instruments, recording equipment etc. are provided for the users. Here the users can also get know-how on staging events and how to present their products. The innovation space represents performative spaces in the form of various types of so-called makerspaces or hackerspaces, in which IT technology is the central hub. These distinctions between the two spaces are not mutually exclusive, but are simplified for the sake of discussion.

\section{Creation space}

An example of the creation space is 'The Garage' in Malmö, Sweden. The Garage is a very small and non-traditional library, housed in a 100 year old garage in a multicultural neighbourhood just outside the city centre. When The Garage opened in 2009 it was more or less empty. The main idea was that the design and the activities within the library should develop naturally, rather than be presented to the public as a finished product. Also, the books in the library are bought on demand and as such The Garage is an ongoing process. As a result, a great deal of effort has been devoted to meeting the requests and needs of the users (Ingefjord 2009). Anyone who wants to do or make something in The Garage is free to do so, furniture can be freely arranged and all equipment is at the disposal of the users. The library provides tools, space and advice, while the users supply the materials and 
ideas. Among the tools available are sewing machines, tools for bicycle repair and everything one needs for knitting and other forms of needlework. As something new, the users are able to borrow 'handy-man' tools and even second-hand clothes. It is also the possible for users to use the library space for staging all kinds of local events, as long as they are open to the public, and in such cases the library will assist with marketing. One could ask, if this actually is a library or rather a community-centre offering handicraft workshops, as seen in the trend of 'bottom-up' community-centres in the late 1960s and 1970s? The participatory culture expressed here is quite low-key, hands-on culture as opposed to more artistic expression or innovation. On the other hand, you could see the Garage as a contribution to a sustainable, non-market culture with its re-furbished building, re-cycled furniture and DIY-approach.

An example of an innovative creative space is the so-called 'Demotek'. Originally it was a Swedish project aimed at making young people's self-produced cultural artefacts available at the library, and thus increasing the number of young users in general. In Denmark the Demotek has been implemented in several libraries, but The Demotek in Copenhagen has instead been marketed as a sort of 'underground library' corresponding with the initial the DIY concept. The Demotek is a place where creative young people can produce and disseminate cultural products with the help of the libraries involved. Each library has a certain place in which the products are displayed. Together with the young users the libraries organise concerts, events, exhibitions and workshops, and in doing so they are not only supporting creativity but also attracting users from a target group which has always been difficult to reach. The Demotek is just one of many creation and co-creation projects to be seen in the Danish library scene in the last years with creation and co-creation as a turning point. The main problem concerning these projects is that the initiatives and activities tend to fade out as the project funding disappears. The result is that the different well-meaning approaches are not actually implemented as an everyday function at the libraries involved and rather become symbols of good intentions with the results of the workshops lingering as relicts, displaced in the library space. One can also ask if the Demotek actually contributes to a more democratic library or if it favour the more 'hip' subcultures at expense of the more mainstream youth.

The issue of favouring certain user groups is addressed in 'Library 10', opened in the centre of Helsinki, Finland in 2005 (Lämsa 2005). In addition to accommodating the city's largest and most varied collection of music, the library is also an IT library. Thus, the library is grounded in young people's competencies and interests. The library is constantly changing its activities and facilities in cooperation with users, and in this way it is up-to-date in a constantly changing media world. Library 10 attracts the digital natives by being technologically updated and by inviting the young people of the city to be creative. Users can borrow musical instruments, and the library provides practice rooms and maintains contact between users who would like to play together. The library offers high quality recording facilities and it provides a stage where both professional musicians and the users of the library can give concerts. Library 10 is connected to a facility called 'Urban Office' where local entrepreneurs can 'rent' an office space for a few hours or a whole day. In this way Library 10 supports the cultural and artistic food chain of the city as well as giving young creative entrepreneurs a chance to meet. But it is still to be proven whether these facilities actually do support the artistic food-chain 
and the development of the creative industry in the city. There is no doubt, that Library 10 has become a great success, and has more than 2000 visitors per day, mostly men between 20 and 30. In this way it has succeeded in addressing the digital natives and changing the normal picture of the from library user as a middle aged, middle class woman.

\section{Innovation space}

In recent years various kinds of workshops and laboratories driven by user participation have arisen. These have been founded in a combination of IT technology development and the emergence of DIY culture, under names such as 'Makerspaces', 'Hackerspaces' 'Peoples Labs' or 'Fab Labs'. Makerspaces is the most common used name, and these names are often used interchangeably and they can be described as a mix of open workshops and communities with interests in using, creating and modifying electronic and digital products or designing new prototypes. Inspired by the US, where different kinds of user-driven technology-based workshops and laboratories have been found in libraries all over the country for some years, this development has now made its entry into Danish public libraries.

The 'Peoples Lab' is a two year development project that examines how libraries in collaboration with their various partners can create open innovation environments. Especially the library of Aarhus, the second largest city in Denmark, has been pioneering the implementation of makerspaces through the establishment of the more general project Among these experiments are 'Pop-up Makerspaces', both within libraries and in places outside in collaboration with local events and festivals, such as 'Tech shops', supporting DIY-culture, and a 'Waste Lab' making it possible to create something new out of unwanted materials. The libraries also make innovative equipment such as 3D scanners and laser cutters freely available to users.

In Valby, on the outskirts of Copenhagen, the library has established a 'Copenhagen FabLab'. A FabLab (fabrication laboratory) is a variation of the makerspace. It is a small scale workshop, equipped with computer controlled tools and various materials, with the objective of supporting personal digital fabrication. FabLab is an international movement that originated at MIT (Massachusetts Institute of Technology) in Boston, USA, aimed at making new technology accessible to ordinary people, and democratizing innovation. In FabLabs the users are allowed to make any kind of personal fabrication and prototype but are not allowed to produce things for sale. According to the international FabLab charter, they are required to share designs and processes with other local and global Fab Lab users, as written on the Copenhagen FabLab homepage: "So the deal is: free use of the machines for things that are not for sale. You "pay" by teaching other users how to use the machines and by sharing your findings with others'. At the time of writing this article, the Copenhagen FabLab (2014) has a digital embroidery machine, a vinyl cutter, a precision milling machine, a laser cutter, a 3D printer, an electronics workbench with measuring equipment, a drill press, a scroll saw and other various hand tools.

The establishment of these spaces and the way they function is still in an experimental phase and is yet to be seen whether they represent just a phase in the development of library 3.0, or whether they will become an integrated part of future libraries. This depends on whether the library has adequate funding to keep up with the newest, cutting-edge technology and whether their staffs has the 
adequate skills to maintain and teach the use of these more advanced tools. It is a question if the makerspaces actually underpin innovation, understood as the invention and prototyping for something new, has not been seen before. On a more strategic level, it is a question whether the designing and development of digital products and new prototypes is seen as a relevant task for libraries.

\section{Discussion}

As we have shown, there has been an emergence and rapid spread of performative spaces in public libraries within the last years. But why have the libraries undertaken this endeavour, which differs from the original idea of the dissemination of quality books to an uneducated public? Looking at the discourses behind the establishment of performative spaces, it is possible to discern at least three rationales: a democratisation rationale aimed at bridging the participation gap, a rationale of economic impact by boosting creativity, innovation and entrepreneurship, and an empowerment rationale giving individuals and groups in society voice and visibility. These rationales are to be discussed below:

\section{Democratisation}

Are the establishment of performative spaces, especially makerspaces, really is a matter for the public library? Why allow all this mess and noise in the usually orderly and quiet library space? Boosting cultural participation is a strategic way to 'lure' reluctant young people into cultural institutions without actually changing the institutions content. According to Simon (2010) developing platforms in which visitors can share ideas and connect with each other in real time give cultural institutions the ability to 'offer changing experiences without incurring heavy ongoing content production costs' (ibid., p. iv). The Demotek and other creative workshops are examples of more or less anchored projects of a limited time span that have a strategic aim to change the image and face of the library, more as a temporary 'make-up' than a profound change.

Introducing active cultural participation in libraries can also be seen from another perspective. Where the challenge earlier was to provide access to content or in other words to bridge the 'information gap', the challenge today is to bridge the 'participation gap' by lowering barriers to enable artistic expression and civic engagement. Not all young people have the same competences for taking advantage of the new interactive media. They are divided into those 'for whom the internet is an increasingly rich, diverse, engaging and simulating resource of growing importance in their lives and those for whom it remains a narrow, un-engaging, if occasionally useful resource of rather less significance' (Livingstone and Bober 2005, p. 12). This is also the reason why the broad but often used terms like 'digital youth' or 'digital natives' may not actually capture the more diverse and complex relationship with digital technology, which in reality characterises the younger generations. Access to production facilities and software are a way to bridge the participation gap by facilitating the production and exchange of artworks in the digital age. According to the American researchers in participatory culture H. Jenkins and V. Bertozzi cultural institutions 'may blur the lines between high art and popular culture, creating a more inviting space for young people to experiment and explore artistic expression of all kinds' (Jenkins 
and Bertozzi 2008, p. 192). In this context, the establishment of performative spaces can be seen as a direct continuation of the basic purpose of the public library, namely to democratise access to information, knowledge and culture.

\section{Economic impact}

The strategic economic importance of creativity, innovation and entrepreneurship in global competition is argued in the discourse, not only in Denmark but also worldwide where 'soft power' is seen as an economic driver on a general level. More specifically, the establishment of a 'food-chain' based on young creative entrepreneurs is seen as important for the development of the creative industries. As Sacco argues: 'The development of a new, successful generation of creative entrepreneurs in Europe is essential to secure the future competitiveness of European cultural and creative productions' (Sacco 2011, p. 8). At the same time, the existence of 'soft power', a visible and authoritative creative and cultural production, underpins the reputation and branding of a country, a region or city on the global market. R. Florida's equation of the three T's: tolerance, talent and technology, can be seen as the background for the creative hype we currently observe in urban development (Florida 2002).

Thus, the legitimization of performative spaces in libraries as underpinning creativity and innovation can be seen as part of the larger picture. Even though the economic rationale is seldom explicitly expressed in the stated missions of creative spaces and innovation spaces, the economic rationale certainly, so to speak, 'puts the public libraries into the picture' and endow them with a proactive, innovative image. In this way the public library can be seen as contributing to the 'food chain', where today's young creative and innovative entrepreneurs will become tomorrow's professionals and as such create economic value, not only within the arts and creative industries themselves but also on a more general economic level. This 'food chain' theory is as previously discussed, still to be proved. One can argue whether the library is the most suitable location for these performative spaces. Do the libraries actually have the necessary expertise and tools to operate as an 'incubator' for future professionals in the cultural or high-tech industries? And even more important: does the pursuing of economic impact undermine other, more basic values of the public library such as its unique role as a non-commercial, public meeting-space?

\section{Empowerment}

The creative and art-related performative spaces in 'the creative library' are in particular meant to give users the potential to strengthen their individual and/or group identity: when young people gather at the Demotek to produce and perform DIY culture they at the same time strengthen their own view of themselves as future artists and part of a subculture. Makerspaces such as FabLabs can also be seen as rooted in an empowerment rationale by giving users new competencies and thus boosting their belief in themselves as innovators and thus part of global high-tech society.

In many respects these 3.0 cultural endeavours can be seen as a new version of the strategy of cultural democracy of the 1970s, which was based on bottom-up organisation, non-market orientation and strengthening individual and group 
identity. According to cultural democracy, the state and municipalities should not only fund art and culture in a narrow sense but also support a broad notion of culture, including the cultural expressions of suppressed groups such as women, children and ethnic groups, and reviving the decaying 'folk culture'. The emergence of this strategy can be seen as result of the 1960s Cultural Revolution, and as a more general reaction against the prevailing strategy of the democratisation of culture, which has been attacked as elitist and exclusive. In practice though, the two strategies have lived peacefully side by side in the Nordic countries (Duelund 2003).

The empowerment rationale which lay behind the strategy of cultural democracy also lies behind the emergence of creative performative spaces, except that now the fiddles and live performances have been replaced by electronic equipment and social media. The idea that young people should also produce 'real' artefacts and live music in face-to-face situations is a reminiscent of the folk-culture revival in the 1970s, in which authenticity and back-to-roots were important features. On the other hand, the more political and liberating element also inherent in the notion of cultural democracy is not as visible today as it was then, where the emancipation of social groups and politicisation of the arts through self-expression in radical spaces prevailed, often in unused industrial buildings. The force of this cultural movement in the 1970s came from 'the people' themselves, whereas today the cultural institutions take the initiative to establish performative spaces, often led by cultural programs with buzz-words such as 'interactive', 'participating', 'user-involvement', 'user-driven innovation' or 'co-creation' as the 'open Sesame' access to public cultural funding.

\section{Conclusion}

As we have demonstrated, the development of the public library is consistent with the three modes of culture from 1.0 towards 3.0: public patronage, marketisation and active cultural participation. It is not, however, possible to speak of a total paradigm shift. Instead the situation can be described as a 'layer-on-layer'-development, where the three cultures live side by side.

Looking specifically at the rationales behind the implementation of performative spaces in the public library, we have shown that several rationales are expressed at the same time. They can be more or less explicit, more or less prevalent and to some degrees, they may overlap. The notion of performative space can thus be seen as legitimized by multiple rationales in the same way that cultural policies and cultural institutions on a more general level are legitimized today: not only by democratisation, but also by economic impact and empowerment.

On the one hand this multi-rationale approach may strengthen the legitimatization of cultural policies and cultural institutions here and now. At a time when public funding is decreasing and the competition from other, more 'hyped' experiences is growing, it may be politically wise to bet on several horses at once. On the other hand, the result could be counter-active in the long run if the results of the rationales do not live up to expectations. This is one of the main dilemmas of cultural policy today: to what degree should support for the arts and creativity be linked to political, economic and social sectors? Can we still speak of an intrinsic value of creative endeavours - professional or non-professional - or are they simply to be seen as nodes in a network of structural interdependencies? Most importantly: does the support for the arts and creativity actually have an impact within these 
sectors or is it more a rhetorical than measurable impact? This requires further investigation.

Finally, it is an interesting question whether the existence of performative spaces in public libraries represent an integrated and long lasting development towards Culture 3.0 or whether it is rather an expression of despair. In other words: is the development of performative spaces a last-ditch effort to make the library more appropriate for the twentyfirst century users or is it an legitimate attempt to justify the library as a hyped and visible cultural institution? Is it a trend which will prove to be temporary and thus disappear when project funding ends and new political winds blow? The latter can be seen as a possible development in a situation where the library is under tremendous pressure both in terms of identity and legitimacy, not least due to the rapid development of the internet and digital technology. Thus, the library searches for new strategies to make itself useful and the creation of performative spaces might be one strategy.

But as this article has shown, the development of performative spaces in libraries offers multiple perspectives. One is a more commercial and unconventional perspective which points towards economic impact with a vision of growth through the support of creativity and innovation. Here the public library will be in competition with other, maybe more suitable public and private initiatives. Other perspectives point towards the notions of democratisation and empowerment of citizens, which always have been core-values of the public library. Seen in this light, the performative space could find a more permanent place in the library integrated with the spaces for learning, inspiration, and meeting.

\section{Disclosure statement}

No potential conflict of interest was reported by the authors.

\section{References}

American Library Association, 2011. Confronting the future: strategic visions for the 21st century public library. Washington: American Library Association.

Bianchini, F., and Parkinson, M., eds., 1993. Cultural policy and urban regeneration: the West European experience. Manchester: Manchester University Press.

Copenhagen FabLab, 2014. Available from: http://kulturogfritid.kk.dk/kultur-valby/copen hagen-fablab [Accessed June 10].

Cummings, Jr., M.C., and Katz, R., eds., 1987. The Patron state. Government and the arts in Europe, North America and Japan. Oxford: Oxford University Press.

Danish Agency for Culture, 2014. Model programme for libraries. Available from: http://modelprogrammer.kulturstyrelsen.dk/en/ [Accessed June 30].

Danish Agency for Library and Media, 2010. The public libraries in knowledge society. Copenhagen: Danish Agency for Library and Media.

Duelund, P., ed., 2003. The Nordic cultural model. Copenhagen: The Nordic Cultural Institute.

Fischer-Lichte, E., 2008. The transformative power of performance: a new aesthetics. London: Routledge/Chapman \& Hall.

Florida, R., 2002. The rise of the creative class. New York: Basic Books.

Hillman-Chartrand, H., and McCaughey, C., 1989. The arms's length principle and the arts. An international perspective - past, present and future. In: M.C Cummings and M.D. Schuster, eds. Who's to pay for the arts? New York: ACA Books, 43-80.

Hvenegaard Rasmussen, C. and Jochumsen, H., 2007. The public library in the customersociety. Proceedings of the 15th BOBCATSSS Symposium, 29-30 January 2007. Prague: Charles University, 180-188. 
Ingefjord, A., 2009. Garaget: all this and books too. Scandinavian public library quarterly, $42(1), 6-9$.

Jenkins, H., 2006. Convergence culture: where old and new media collide. New York: University Press.

Jenkins, H. and Bertozzi, V., 2008. Artistic expression in the age of participatory culture. In: S.J. Tepper and B. Ivey, eds. Engaging art - the next great transformation of America's cultural life. New York: Routledge, 171-197.

Jochumsen, H., Hvenegaard Rasmussen, C., and Skot-Hansen, D., 2012. The four spaces a new model for the public library. New library world, 113 (11/12), 586-597.

Kemp, R.L. and Trotta, M., 2008. Museums, libraries and urban vitality: a handbook. Jefferson: McFarland \& Company.

Lämsa, K., et al., 2005. Library 10 and meetingpoint@lasipalat. Scandinavian public library quarterly, 38 (4), 20-23.

Livingstone, S. and Bober, M., 2005. UK children go online. London: Economic and Social Research Council.

McGuigan, J., 2004. Rethinking cultural policy. Maidenhead: Open University Press.

Mickelson, P., 1975. American Society and the Public Library in the thought of Andrew Carnegie. Journal of library history, 10 (2), 117-138.

Palfrey, J. and Gasser, U., 2008. Born digital: understanding the first generation of digital natives. New York: Basic Books.

Pine, J. and Gilmore, J.H., 1999. The experience economy. Work is a theatre and every business a stage. Boston: Harvard Business Press.

Ritzer, G., Dean, P., and Jurgenson, N., 2012. The coming of age of the prosumer. American behavioral scientist, 56 (4), 379-398.

Sacco, P.L., ed., 2011. Culture 3.0: a new perspective for the EU 2014-2020 structural funds programming. Produced for the OMC working group on cultural and creative industries, April 2011 on behalf of the European expert network on culture (EENC).

Simon, N., 2010. The participatory museum. Santa Cruz: MUSEUM 2.0.

Skot-Hansen, D., 2002. Why cultural policy? In: J. Robinson, ed. EUROCULT21 Integrated report. Helsinki: City of Helsinki Cultural Office, 31-39.

Skot-Hansen, D., Hvenegaard Rasmussen, C., and Jochumsen, H., 2013. The role of public libraries in culture-led urban regeneration. New library world, 114 (1/2), 7-19.

Spencer, A., 2005. DIY: the rise of Lo-fi culture. London: Marion Boyars.

Stevenson, S., 2010. The political economy of Andrew Carnegie's library philanthropy, with a reflection on its relevance to the philanthropic work of Bill Gates. Library and information history, 26 (4), 237-257.

Vestheim, G., 1994. Instrumental cultural policy in scandinavian countries: a critical historical perspective. The European journal of cultural policy, 1 (1), 57-71. 